\title{
How can I safely return to work after maternity leave?
}

\author{
Abi Rimmer
}

\section{BMJ Careers}

\section{"Good childcare is crucial"}

Laura Hamilton, consultant orthopaedic hand surgeon at Brighton and Sussex University Hospital, says, "Returning to work after months of maternity leave is daunting. Some people attend paid 'keep in touch' days to keep their skills up, however everything comes back to you very quickly once you start.

"When returning to work, a mother may ask for less than full time working arrangements, but an employer is under no obligation to agree. Following the Deech Report on women doctors, ${ }^{1}$ the General Medical Council began working with the royal colleges to improve access to flexible training and part time working. If a worker is breast feeding, their employer must support them with facilities to rest and pump, as well as a fridge to store collected breast milk.

"Good childcare is crucial for a smooth return to work. Unfortunately, long hours and shift work can be difficult to plan for. Hospital nurseries often have the longest hours but the waiting lists can be long, so register your baby at birth.

"You will also need supportive family or friends to help when you are inevitably called to collect your child because of rashes or diarrhoea. However, both parents are entitled to 13 weeks' unpaid emergency parental leave in the first five years. A nanny gives you more flexibility and they will look after a poorly child. Salary sacrifice childcare vouchers are a tax efficient way to pay nurseries or Ofsted registered nannies, and there are government child benefits until the child is 19."

\section{"Don't take on too much"}

Naeem Nazem, medical adviser at the Medical and Dental Defence Union of Scotland, says "Although returning to work can be a daunting prospect, doctors can make sure they have a smooth transition by adopting a few measures in advance.

"All doctors who take a significant break from clinical practice have a professional duty to ensure they are safe to return. You may feel motivated to take on all your previous clinical duties, or even feel pressured to do so by your colleagues, but it's important that you don't try to take on too much, too soon. Ensure that you work within your own competence so that patient safety isn't compromised.

"When you are planning your return to work it may be helpful to talk to your clinical supervisor, appraiser, or employing organisation. They can provide you with practical steps to ensure that your skills are up to date.

"You could create a personal development plan to help you pinpoint any areas that need attention. The GMC's continued professional guidance on career breaks highlights the importance of making sure you are up to date with any developments within your specialty.

"If you are still concerned about your skill levels or you feel you would benefit from further support, then you could ask for a period of shadowing, observation, or mentoring.

"The Academy of Medical Royal Colleges has guidance on returning to practice, including details on appropriate processes being in place to safeguard patient safety.

"Finally, check that any deferred membership of your medical defence organisation is reinstated ahead of your return."

\section{"Get support if you need it"}

Emma Plunkett, consultant anaesthetist in the west Midlands, says "Returning to work safely involves making sure you are prepared and feeling supported. Preparation includes refreshing both your knowledge and skills, and organising childcare you are happy with so you can focus on your work.

"Attending a return to work (RTW) course is a good way of refreshing your knowledge and skills. Some specialties run specific courses but if there isn't one available, you could use a 'keeping in touch' day to attend a relevant course or conference. $^{23}$

"In my experience, technical skills come back reasonably quickly. Non-technical skills can feel harder and this is why a supervised re-introduction is important, and why, if possible, it's helpful to return to the workplace from which you left. This ensures logistical aspects are familiar, giving you more headspace to devote to your clinical skills.

"Feeling supported involves having a structured RTW programme, a mentor who can help you work out what is right for you, and colleagues who you can ask when unsure. Your department should make sure all this is available. Your RTW programme must include an induction into your organisation and department, and a plan for supervised sessions in all areas you will work in. 
"Being safe involves being aware of one's limitations and having support when needed. It's okay to ask for help, however senior you are. Good luck."

1 Deech R. Women doctors: making a difference. Report of the Chair of the National Working Group on Women in Medicine. 2009. www.nwpgmd nhs uk/sites/default/files/WIMreport. pdf.
2 Royal College of Anaesthetists. Giving anaesthesia safely again. www.rcoa.ac.uk/ GASAgain.

3 NHS Forth Valley. Return to emergency medicine. https://scschforg/product/return-toemergency-medicine-2.

Published by the BMJ Publishing Group Limited. For permission to use (where not already granted under a licence) please go to http://group.bmj.com/group/rights-licensing/ permissions 